\title{
HUBUNGAN STATUS FUNGSIONAL DENGAN TINGKAT DEPRESI PADA PASIEN STROKE DI RUANG FLAMBOYAN RSUD JOMBANG
}

\author{
The Correlation Of Functional Status With Depression Level For Stroke Patients \\ In Flamboyan Room RSUD Jombang
}

\author{
Windya Noor Vika*, Anis Satus Syarifah, Mamik Ratnawati \\ Stikes Pemkab Jombang \\ *Email : windyanoorvika@gmail.com
}

\begin{abstract}
ABSTRAK
Pendahuluan: Stroke meningkat pada dasawarsa terakhir dan merupakan penyakit utama penyebab kecacatan, stroke mengakibatkan pasien mengalami ketergantungan karena keadaannya, stroke disertai kecacatan berdampak pada penerimaan individu tercermin pada perilakunya yang menjadikan depresi. Penelitian ini bertujuan untuk mengetahui hubungan status fungsional dengan tingkat depresi pada pasien stroke di Ruang Flamboyan RSUD Jombang. Metode: Desain penelitian mengunakan Analitik Korelasi dengan Cross Sectional, Populasi penelitian ini pasien stroke infark di Ruang Flamboyan RSUD Jombang sebanyak 96 orang. Teknik sampling yang digunakan adalah Consecutive Sampling, jumlah sampel 48 orang. Variabel independennya adalah status fungsional sedangkan Variabel dependennya adalah tingkat depresi. Pengumpulan data menggunakan kuesioner. Data dianalisis menggunakan uji Kendal Tau. Hasil: Berdasarkan hasil penelitian pada tanggal 4 - 25 April 2017 didapatkan sebagian besar $(58,3 \%)$ responden ketergantungan berat dan tingkat depresi hampir setengah $(37,5 \%)$ responden kategori depresi sedang, hasil uji statistik menggunakan Kendal Tau diketahui ada hubungan antara status fungsional dengan tingkat depresi pada pasien stoke di Ruang Flamboyan RSUD jombang. Angka korelasi 0,611 menunjukkan kekuatan di dalam penelitian ini kuat. Pembahasan: Berdasarkan penelitian yang dilakukan tentang hubungan status fungsional dengan tingkat depresi pasien stroke diharapkan dapat mengetahui penyebab dan tanda gejala depresi sehingga dapat melakukan pencegahan terhadap faktor-faktor penyebab depresi serta mengurangi ketergantungan kepada orang lain dan meningkatkan status fungsional khususnya pada penderita stroke di Ruang Flamboyan RSUD Jombang.
\end{abstract}

Kata Kunci : Status Fungsional, Tingkat Depresi, Stroke

\begin{abstract}
Introduction: Stroke increased in the last decade and it is the main disease which causes disability, stroke results patients become dependency because of their condition, stroke is accompanied by disability which affects individual acceptance is reflected in their behavior that makes depression. This research aimed to determine the correlation of functional status with depression level for stroke patients in the room of Flamboyan RSUD Jombang. Methods: The research design used Correlation Analysis with Cross Sectional. The population of this research was stroke infarction patients in the room of Flamboyan RSUD Jombang as many as 96 people. Sampling technique used Consecutive Sampling, the number of samples was 48 people. Independent variable was functional status whereas Dependent variable was depression level. Data collection used questionnaires. Data was analyzed by using Kendal Tau test. Result: Based on the result of the research on 4-25 April 2017, it was obtained that the most respondents (58,3\%) got heavy dependency and depression level was almost half (37,5\%) respondents got medium depression category, statistical test result used Kendal Tau that has been known that there was correlation between functional status and depression level for stoke patients in the room of Flamboyan RSUD Jombang. The number of correlation 0.611 indicated that the strength in this research was strong.Discussion: Based on research that was done about the correlation of functional status with depression level for stroke patients which is expected to be able to know the cause and sign of depression symptoms so that it can do prevention to the factors which cause depression and also reduce dependence to others and improve functional status especially for stroke patients in the room of Flamboyan RSUD Jombang.
\end{abstract}

Keywords: Functional Status, Depression Level, Stroke 


\section{PENDAHULUAN}

Menurut Yayasan Stroke Indonesia (Yastroki), meningkatnya jumlah penyandang stroke di Indonesia dalam dasawarsa terakhir (Dourman, 2013). Stroke menjadikan seseorang tergantung dengan orang lain dan setelah stroke biasanya terjadi perubahan penerimaan diri individu yang tercermin dalam perilakunya. (Khomsiatun, 2015). Menghadapi mundurnya mobilitas, kekuatan fisik, kesulitan kerja, hobi, kemampuan kognitif akan mencetuskan munculnya depresi, sekitar 26-60\% penderita stroke menunjukkan gejala klinis depresi (Lumbantobing, 2011).

Menurut Perhimpunan Dokter Spesialis Jiwa Indonesia menyatakan insiden depresi pasca stroke berkisar 11-68\% pada 3-6 bulan pasca stroke dan tetap tinggi sampai 1 -3 tahun kemudian (Gumilan, 2013). Sekitar 15$25 \%$ pasien stroke dirawat di rumah menderita depresi, sedangkan pasien yang dirawat di rumah sakit 30-40\% menderita depresi (Apridawati, 2010 dalam Rosita, 2012).

Semakin meningkatnya prevalensi stroke dan dampaknya yang sangat besar serta belum adanya penanganan yang berhubungan dengan status fungsional dapat menyebabkan kecacatan semakin berat (Rachmawati, Utomo, Nauli, 2012). Hal tersebut berakibat pada penerimaan diri individu pasien bereaksi dengan kemarahan terhadap kehilangan yang dapat diarahkan kepada diri sendiri dan terjadinya depresi (Bramastyo, 2009 dalam Khomsiatun 2015).

Penanganan masalah emosional dapat dilakukan dengan psikoterapi, farmakoterapi, terapi elektrokonvulsif bila depresinya parah, depresi dapat dikurangi dengan meningkatkan kegiatan yang menyenangkan, dan mandiri (Lumbantobing, 2011).

Berdasarkan latar belakang peneliti tertarik melakukan penelitian tentang Hubungan Status Fungsional Dengan Tingkat Depresi Pada Pasien Stroke Di Ruang Flamboyan RSUD Jombang.

\section{METODE PENELITIAN}

Desain penelitian ini adalah Analitik Korelasi dengan pendekatan Cross Sectional. Penelitian dilakukan di Ruang Flamboyan RSUD Jombang pada bulan April 2017. Populasinya sebanyak 1155 orang dengan jumlah sampel sebanyak 48 orang, untuk variabel independen adalah status fungsional sedangkan variabel dependennya adalah tingkat depresi dengan menggunakan tehnik sampling Consecutive Sampling.

Pengukuran status fungsional dengan kuesioner Indeks Barthel. Sedangkan untuk tingkat depresi digunakan kuesioner HDRS. Analisis data menggunakan Uji Statistik Kendall Tau.

\section{HASIL PENELITIAN}

Pada bagian ini diuraikan tentang data umum usia, pekerjaan, komplikasi penyakit, pendidikan, dukungan keluarga, dan stroke yang berulang dan untuk data khusus akan membahas status fungsional, tingkat depresi dan hubungan status fungsional dengan tingkat depresi pada pasien stroke di RSUD Jombang yang akan disajikan dalam bentuk tabel.

Tabel 1 menunjukkan bahwa hasil usia hampir setengah $(43,7 \%)$ responden berusia pertengahan / middle age (45-59 tahun), pekerjaan sebagian besar $(52,1 \%)$ responden sudah tidak bekerja, hasil komplikasi penyakit penelitian ini sebagian besar $(60,4 \%)$ responden terdapat komplikasi penyakit, pendidikan dalam penelitian ini menunjukkan bahwa sebagian besar $(62,5 \%)$ responden pendidikan dasar, dukungan keluarga menunjukkan bahwa hampir seluruhnya $(95,8 \%)$ responden dukungan keluarga baik dan untuk serangan berulang menunjukkan bahwa hampir seluruhnya $(79,2 \%)$ responden tidak mengalami serangan stroke berulang.

Tabel 2 menunjukkan bahwa sebagian besar $(58,3 \%)$ responden status fungsional dalam ketergantungan.

Tabel 3 menunjukkan bahwa hampir setengah $(37,5 \%)$ responden tingkat depresi kategori sedang.

Tabel 4 menunjukkan bahwa sebagian besar $(53,6 \%)$ responden status fungsional ketergantungan berat mengalami depresi berat. 
Tabel 1 Distribusi Frekuensi Data Umum Responden Di Ruang Flamboyan RSUD Jombang

\begin{tabular}{|c|c|c|c|}
\hline No & Data Umum & Frekuensi & Presentase (\%) \\
\hline 1 & $\begin{array}{c}\text { Usia } \\
\text { 36-44 tahun } \\
\text { 45-59 tahun } \\
\text { 60-74 tahun } \\
\text { 75-90 tahun } \\
>90 \text { tahun }\end{array}$ & $\begin{array}{c}3 \\
21 \\
17 \\
7 \\
0\end{array}$ & $\begin{array}{c}6,3 \\
43,7 \\
35,4 \\
14,5 \\
0\end{array}$ \\
\hline 2 & $\begin{array}{c}\text { Pekerjaan } \\
\text { Bekerja } \\
\text { Sudah tidak bekerja }\end{array}$ & $\begin{array}{l}23 \\
25\end{array}$ & $\begin{array}{l}47,9 \\
52,1\end{array}$ \\
\hline 3 & $\begin{array}{c}\text { Komplikasi penyakit } \\
\text { Ya } \\
\text { Tidak }\end{array}$ & $\begin{array}{l}29 \\
19\end{array}$ & $\begin{array}{l}60,4 \\
39,6\end{array}$ \\
\hline 4 & $\begin{array}{c}\text { Pendidikan } \\
\text { Dasar } \\
\text { Menengah } \\
\text { Tinggi }\end{array}$ & $\begin{array}{c}36 \\
9 \\
3\end{array}$ & $\begin{array}{c}75 \\
18,8 \\
6,3\end{array}$ \\
\hline 5 & $\begin{array}{c}\text { Dukungan keluarga } \\
\text { Baik } \\
\text { Tidak baik }\end{array}$ & $\begin{array}{c}46 \\
2\end{array}$ & $\begin{array}{c}95,8 \\
4,2\end{array}$ \\
\hline 6 & $\begin{array}{c}\text { Stroke berulang } \\
\text { Ya } \\
\text { Tidak }\end{array}$ & $\begin{array}{l}10 \\
38\end{array}$ & $\begin{array}{l}20,8 \\
79,2\end{array}$ \\
\hline
\end{tabular}

Sumber : Data Primer 2017

Tabel 2 Distribusi Frekuensi Status Fungsional Pada Pasien Stroke di Ruang Flamboyan RSUD Jombang

\begin{tabular}{cccc}
\hline No & Status fungsional & Frekuensi & Presentase (\%) \\
\hline 1 & Ringan & 1 & 2,1 \\
2 & Sedang & 12 & 25,0 \\
3 & Berat & 28 & 58,3 \\
4 & Sangat berat & 7 & 14,6 \\
\hline & Total & 48 & 100
\end{tabular}

Sumber : Data Primer 2017

Tabel 3 Distribusi Frekuensi Tingkat Depresi Pada Pasien Stroke di Ruang Flamboyan RSUD Jombang

\begin{tabular}{cccc}
\hline No & Tingkat depresi & Frekuensi & Presentase (\%) \\
\hline 1 & Ringan & 6 & 12,5 \\
2 & Sedang & 18 & 37,5 \\
3 & Berat & 16 & 33,3 \\
4 & Sangat berat & 8 & 16,7 \\
\hline & Total & 48 & 100 \\
\hline
\end{tabular}

Sumber : Data Primer 2017

Tabel 4 Tabulasi Silang Antara Status Fungsional Dengan Tingkat Depresi Pasien Stroke di Ruang Flamboyan RSUD Jombang

\begin{tabular}{|c|c|c|c|c|c|c|c|c|c|c|}
\hline \multirow{3}{*}{$\begin{array}{c}\text { Status } \\
\text { fungsional }\end{array}$} & \multicolumn{8}{|c|}{ Depresi } & \multirow{2}{*}{\multicolumn{2}{|c|}{ Total }} \\
\hline & \multicolumn{2}{|c|}{ Ringan } & \multicolumn{2}{|c|}{ Sedang } & \multirow{2}{*}{$\frac{\text { Berat }}{\mathrm{f}}$} & \multicolumn{3}{|c|}{ Sangat berat } & & \\
\hline & $\mathrm{F}$ & $\%$ & f & $\%$ & & $\%$ & $\mathrm{f}$ & $\%$ & $\mathrm{~F}$ & $\%$ \\
\hline Ringan & 1 & 100 & 0 & 0 & 0 & 0 & 0 & 0 & 1 & 100 \\
\hline Sedang & 5 & 41,7 & 7 & 58,3 & 0 & 0 & 0 & 0 & 12 & 100 \\
\hline Berat & 0 & 0 & 9 & 32,1 & 15 & 53,6 & 4 & 14,3 & 28 & 100 \\
\hline Total & 0 & 0 & 2 & 28,6 & 1 & 14,3 & 4 & 57,1 & 7 & 100 \\
\hline Total & 6 & 12,5 & 18 & 37,5 & 16 & 33,3 & 8 & 16,7 & 48 & 100 \\
\hline
\end{tabular}

Sumber : Data Primer 2017 
Hasil Uji statistik menggunakan Kendall Tau didapatkan $\mathrm{p}$ value $0,000 \leq 0,05$ sehingga ada hubungan yang signifikan antara status fungsional dengan tingkat depresi pada pasien stoke di ruang flamboyan RSUD Jombang. Angka korelasi 0,611 kekuatan hubungan kuat.

\section{PEMBAHASAN}

\section{Status Fungsional Pasien Sroke Di Ruang Flamboyan RSUD Jombang}

Berdasarkan tabel 2 didapatkan bahwa bahwa sebagian besar $(58,3 \%)$ responden status fungsional dalam ketergantungan berat.

Keadaan tersebut dimungkinkan dipengaruhi oleh usia, pekerjaan, komplikasi penyakit, pendidikan, dukungan keluarga dan stroke berulang.

Faktor pertama yang mempengaruhi status fungsional adalah usia, pada penelitian ini didapatkan sebagian besar $(61,9 \%)$ responden usia pertengahan (middle age) 4559 tahun dengan status fungsional ketergantungan berat.

Dalam penelitian ini usia paling banyak usia pertengahan (middle age).Hal ini terjadi karena Orang berusia lanjut umumnya tidak berespon terhadap lingkungan internal yang berubah, cenderung membuat lansia sulit untuk memelihara kestabilan status fisik dan kimiawi dalam tubuh. Gangguan terhadap homeostasis tersebut dapat memudahkan terjadinya disfungsi berbagai sistem organ dan turunnya toleransi terhadap obat-obatan (Stiati, 2007 dalam Khomsiatun,2015).

Berdasarkan penelitian yang dilakukan oleh peneliti faktor yang menjadikan seperti itu karena pasien yang biasanya produktif dan mampu melakukan kegiatan sendiri tiba-tiba sakit terjadi kecacatan yang dapat menjadikan pasien lebih tergantung terhadap orang lain.

Faktor kedua yang mempengaruhi status fungsional adalah pekerjaan, pada penelitian ini didapatkan sebagian besar $(56,0 \%)$ responden pasien stroke yang sudah tidak bekerja status fungsional dalam ketergantungan berat.

Menurut Muttaqin, 2008 dalam Marjoko (2014) yang menyatakan bahwa stroke merupakan penyakit yang paling sering menyebabkan cacat berupa kelumpuhan anggota gerak, gangguan bicara, proses berpikir, daya ingat, dan bentuk-bentuk kecacatan lain sebagai akibat gangguan fungsi otak. Kehilangan fungsi tubuh akibat penyakit stroke mengakibatkan produktifitas pasien stroke terhalang dan berpengaruh pada status fungsional pasien stroke (Junaidi, 2011 dalam Marjoko, 2014).

Berdasarkan penelitian yang dilakukan oleh peneliti faktor yang menjadikan pasien seperti itu adalah biasanya pasien aktif beraktivitas dan setelah sakit pasien sudah tidak bekerja dan menjadi lebih bergantung dengan orang lain.

Faktor ketiga yang mempengaruhi status fungsional adalah komplikasi penyakit. Pada penelitian ini didapatkan sebagian besar $(51,7 \%)$ responden pasien stroke yang memiliki komplikasi penyakit status fungsional dalam ketergantungan berat.

Menurut Yatinde (2013), dengan adanya komplikasi penyakit pengobatan tidak hanya berfokus pada penyakit stroke saja sehingga akan mempengaruhi kecepatan kesembuhan dan juga bila komplikasi penyakit tidak diobati dapat pula memperburuk keadaan stroke. Pasien yang memiliki penyakit berat, seperti hipertensi, kencing manis, penyakit jantung, ginjal, cenderung pulih lebih lambat dibandingkan mereka yang tidak mengidap penyakit tersebut (Junaidi, 2011: 64 dalam Yatinde, 2013).

Berdasarkan penelitian yang dilakukan oleh peneliti faktor yang menjadikan keadaan pasien seperti itu karena komplikasi penyakit seperti hipertensi, jantung dan DM, hal ini terjadi karena ketidakberdayaannya yang disebabkan oleh stroke yang menjadikan pasien lebih tergantung dan keadaan memburuk karena adanya komplikasi penyakit lain.

Faktor keempat yang mempengaruhi status fungsional adalah pendidikan. Pada penelitian ini didapatkan sebagian besar $(58,3 \%)$ responden pasien stroke yang pendidikan dasar status fungsional dalam ketergantungan berat.

Menurut Aminah et al. (2008) dalam Ratnasari (2010) mengemukakan bahwa tingkat pendidikan terakhir memiliki efek pada usia dan status kesehatan. Pendidikan rendah pada orang tua dengan tingkat sosial ekonomi menengah ke bawah akan lebih mudah jatuh pada kondisi kesehatan yang buruk. Sehingga pendidikan berpengaruh terhadap tingkat kesehatan yang rendah.

Berdasarkan penelitian yang dilakukan oleh peneliti faktor yang menjadikan seperti itu karena kurangnya informasi karena pendidikan rendah tidak banyak mengerti tentang apa yang harus dilakukan mengakibatkan pasien lebih membutuhkan bantuan orang lain.

Faktor kelima mempengaruhi status fungsional adalah dukungan keluarga. Pada penelitian ini didapatkan sebagian besar $(58,7 \%)$ responden pasien stroke yang 
dukungan keluarga baik status fungsional dalam ketergantungan berat.

Dukungan keluarga akan dapat membantu proses perawatan pasien agar penderita stroke dapat melakukan aktivitas kembali meskipun tidak sepenuhnya kembali normal. Adanya dukungan keluarga yang optimal, akan menyebabkan penderita stroke menjadi mandiri dalam melakukan aktivitas dan apabila tidak ada dukungan keluarga maka pasien stroke menjadi ketergantungan kepada orang lain dalam pemenuhan ADL (Karunia, 2016).

Berdasarkan penelitian yang dilakukan tidak sesuai dengan teori yang ada faktor yang menjadikan seperti itu mungkin keluarga hanya terfokus pada psikologisnya saja tetapi tidak diikuti dengan perbaikan fisik pasien.

Faktor keenam mempengaruhi status fungsional adalah stroke berulang. Pada penelitian ini didapatkan sebagian besar $(55,3 \%)$ responden pasien stroke yang tidak mengalami stroke berulang status fungsional dalam ketergantungan berat.

Menurut Sulistyawati (2017) Stroke berulang sering mengakibatkan status fungsional yang lebih buruk dari pada stroke pertama. Kecacatan dan kematian yang timbul pada kasus stroke berulang jauh lebih tinggi daripada kasus stroke serangan pertama. Hal ini dikarenakan pada stroke berulang terjadi defisit neurologik yang berbeda dengan stroke yang pertama (Amelia, 2012 dalam Oktaviani, 2017).

Berdasarkan penelitian yang dilakukan tidak sesuai dengan teori yang ada faktor yang menjadikan seperti itu karena pasien yang baru pertama kali mengalami stroke dan terjadi defisit neurologis pada otak yang biasanya bisa beraktivitas mandiri setelah sakit menjadi cacat dan bergantung pada orang lain.

\section{Tingkat Depresi Pasien Stroke Di Ruang Flamboyan RSUD Jombang}

Berdasarkan tabel 3 menunjukkan bahwa hampir setengah $(37,5 \%)$ responden tingkat depresi kategori sedang.

Keadaan tersebut dimungkinkan dipengaruhi oleh usia, pekerjaan, komplikasi penyakit, pendidikan, dukungan keluarga dan stroke berulang.

Faktor pertama yang mempengaruhi tingkat depresi adalah usia. Pada penelitian ini didapatkan hampir setengah $(42,8 \%)$ responden merupakan usia pertengahan (middle age) 45-59 tahun dengan tingkat depresi berat.

Glamcevski et al (2002) dalam Hayulita (2014) menyatakan bahwa usia lanjut sebagai faktor resiko terjadinya depresi. Menurut
Pradita (2016) Kejadian depresi pada stroke ini semakin meningkat dengan meningkatnya umur penderita. Bertambahnya umur diasumsikan terjadi penurunan kemampuan tubuh untuk beradaptasi dengan stress lingkungan, perubahan fungsi fisik, kognitif sampai perubahan psikososial yang akan mempermudah terjadinya depresi pada lansia (Sadock dan Sadock, 2010 dalam Pradita, 2016).

Berdasarkan penelitian yang dilakukan oleh peneliti faktor yang menjadikan seperti itu karena fungsi tubuh usia pertengahan (middle age) sudah menurun dan menurun juga fungsi koping dalam dirinya terhadap stressor yang ada.

Faktor kedua yang mempengaruhi tingkat depresi adalah pekerjaan. Pada penelitian ini didapatkan hampir setengah $(44,0 \%)$ responden pasien stroke yang sudah tidak bekerja tingkat depresi dalam kategori sedang.

Menurut Engstrom, et al. (2005) dalam Karunia (2016) menyebutkan bahwa stres akibat kerja inilah yang menjadi faktor pemicu terjadinya stroke. Dari hasil wawancara Responden pada awalnya bekerja, namun setelah terserang stroke menjadi tidak bekerja anggota gerak tubuh tidak dapat digunakan untuk melakukan pekerjaan sehingga menjadi tidak produktif.

Berdasarkan penelitian yang dilakukan oleh peneliti faktor yang menjadikan seperti itu karena pasien yang biasanya aktif beraktivitas dan bersosialisasi dengan teman kerjanya sudah tidak bisa lagi bekerja karena penyakitnya pasien akan mengalami perubahan pada penerimaan diri individu yang dapat menjadikan pasien mengalamai depresi.

Faktor ketiga yang mempengaruhi tingkat depresi adalah komplikasi penyakit. Pada penelitian ini didapatkan hampir setengah $(37,9 \%)$ responden pasien stroke yang memiliki komplikasi penyakit tingkat depresi dalam kategori sedang.

Menurut Rahimi, Ahmadi dan Gholyaf (2008) dalam Darussalam (2011) menyatakan bahwa depresi merupakan respon psikologis terhadap penyakit kronis. Penyakit kronis disini bisa berupa stroke dan ketika seseorang mempunyai lebih dari satu penyakit kronis maka akan bertambah pula depresinya.

Berdasarkan penelitian yang dilakukan oleh peneliti faktor yang menjadikan seperti itu karena penyakit stroke itu sendiri memiliki efek depresi yang jika pasien memiliki komplikasi penyakit lain seperti DM, Hipertensi dan jantung akan semakin memperburuk keadaan dan pengobatan tidak hanya berfokus pada pengbatan fisik tetapi juga pada pengobatan psikisnya. 
Faktor keempat yang mempengaruhi tingkat depresi adalah pendidikan pada penelitian ini didapatkan hampir setengah $(40,0 \%)$ responden pasien stroke tingkat pendidikan dasar tingkat depresi dalam kategori sedang.

Menurut Lievre, Alley dan Crimmins (2010) dalam Pradita (2016) pendidikan yang rendah berkaitan dengan depresi terutama pada usia lanjut, hal ini karena orang-orang dengan pendidikan yang lebih rendah akan mencapai usia tua dengan penurunan kognitif dan kesehatan fisik yang buruk.

Hal ini terjadi karena tingkat pendidikan mempengaruhi seseorang dalam depresi, semakin tinggi tingkat pendidikan seseorang, semakin mudah menerima informasi sehingga semakin banyak pula pengetahuan yang dimiliki. Sebaliknya pendidikan yang kurang akan menghambat perkembangan sikap seseorang terhadap nilai yang diperkenalkan, (Nursalam 2001, dalam Puspitasari 2011 dalam yatinde 2013).

Berdasarkan penelitian yang dilakukan oleh peneliti faktor yang menjadikan seperti itu karena kebanyakan responden dalam kategori lansia usia pertengahan (middle age) yang tidak terlalu faham informasi tentang masalah penyakit dan kejiwaan yang ada terlebih stroke itu sendiri memiliki efek psikologis salah satunya adalah depresi.

Faktor kelima yang mempengaruhi tingkat depresi adalah dukungan keluarga, pada penelitian ini didapatkan hampir setengah $(39,1 \%)$ responden pasien stroke yang memiliki dukungan keluarga baik tingkat depresi dalam kategori sedang.

Dukungan keluarga ada empat macam dukungan keluarga yaitu dukungan instrumental, dukungan penghargaan, dukungan emosional dan dukungan informasi. Pada dukungan instrumental, keluarga berperan sebagai sumber pertolongan yang praktis dan fasilitas selama masa perawatan. Keluarga bertindak sebagai perantara antara penderita stroke dengan pelayanan kesehatan, Selain itu hal lain yang dapat dilakukan keluarga adalah membantu penderita apabila mengalami kesulitan dalam melakukan suatu hal. Dukungan ini paling efektif apabila dihargai oleh penderita dan dapat mengurangi depresi (Karunia, 2016).

Berdasarkan penelitian yang dilakukan oleh peneliti faktor yang menjadikan seperti itu karena pasien yang memiliki keluarga yang aktif diajak berkomunikasi dan memiliki keluarga yang care dapat memberikan motivasi agar mereka tetap semangat dalam mengahadapi penyakitnya.

Faktor keenam mempengaruhi tingkat depresi adalah stroke berulang .pada penelitian ini didapatkan hampir setengah $(36,8 \%)$ responden pasien stroke yang tidak mengalami stroke berulang tingkat depresi dalam kategori sedang.

Menurut Fatoye dalam Hayulita 2014 yang menyatakan bahwa lama menderita stroke akan mempengaruhi kondisi seseorang dalam menerima keadaan fisiknya. Hal ini terjadi karena lamanya pemulihan dan stroke sering kambuh dan semakin banyak faktor yang dijumpai maka makin tinggi kemungkinan depresi pada stroke.

Berdasarkan penelitian yang dilakukan oleh peneliti faktor lain yang mempengaruhi karena mungkin kejadian stroke yang pertama yang membuat pasien takut dan tidak bisa mengontrol stressor yang ada.

\section{Hubungan Status Fungsional Dengan Tingkat Depresi Pada Pasien Stroke Di Ruang Flamboyan RSUD Jombang}

Berdasarkan tabel 4 menunjukkan bahwa sebagian besar $(53,6 \%)$ responden pasien stroke di Ruang Flamboyan RSUD Jombang status fungsional dalam ketergantungan berat mengalami depresi berat.

Stroke penyebab utama gangguan fungsional, dimana $20 \%$ penderita yang bertahan hidup masih membutuhkan perawatan di institusi kesehatan setelah 3 bulan dan $15-30 \%$ penderitanya mengalami cacat permanen (Yenni, 2011). Sekitar 90\% pasien stroke mengalami kecacatan atau kelumpuhan separuh badan. Hal tersebut berakibat pada perubahan penerimaan diri individu jika peneriman diri seseorang rendah, akan berdampak pada kesehatan mentalnya yang akan memicu timbulnya gangguan mental seperti depresi (Lubis, 2009 dalam Khomsiatun, 2015).

Hasil uji statistik menggunakan Kendall Tau didapatkan $p$ value $0,000 \leq 0,05$ diketahui ada hubungan antara status fungsional dengan tingkat depresi pada pasien stroke di Ruang Flamboyan RSUD Jombang. Hasil uji didapatkan angka korelasi 0,611 dengan kategori kuat.

Teori keperawatan yang digunakan dalam penelitian ini adalah teori perawatan mandiri (self-care) dikemukakan oleh Dorothea E.Orem pada tahun 1971 dan dikenal dengan teori deficit perawatan diri (self-care deficit nursing theory-SCDNT) (Delauna \& Ladner,2002 dalam Nursalam,2016). Teori SCDNT sebagai teori besar yaitu teori self-care, teori self-care deficit, dan teori nursing system (Alligod \& Tomey, 2006 dalam Nursalam, 2016). Teori self care defisit Orem mengatakan bahwa 
bahwa jika seseorang tidak cukup mampu untuk merawat dirinya sendiri berkaitan dengan kesehatannya maka ia dikatakan menderita defisit perawatan diri (Orem, 1985 dalam Basford \& Slevin, 2006 dalam Nursalam, 2016).

\section{KESIMPULAN DAN SARAN}

\section{Kesimpulan}

Berdasarkan hasil penelitian di dapatkan Status fungsional pasien stroke infark yang dirawat di Ruang Flamboyan RSUD Jombang Sebagian besar $(58,3 \%)$ mengalami ketergantungan berat, Tingkat depresi Hampir setengah $(37,5 \%)$ mengalami depresi sedang Dan Ada hubungan antara status fungsional dengan tingkat depresi pada pasien stroke di Ruang Flamboyan RSUD Jombang dengan kategori kuat.

\section{Saran}

Bagi peneliti selanjutnya, disarankan untuk mampu memasukkan variabel lain seperti gangguan kognitif, jenis stroke dan motivasi.

Bagi institusi pendidikan, Diharapkan dapat dijadikan sebagai bahan referensi pustaka dan penelitian ini dapat digunakan sebagai konsep ilmu yang dapat dijadikan bahan ajar dalam menghadapi masalah kejiwaan pada penderita stroke.

Bagi Pasien Stroke, Penelitian ini menjadi informasi dan landasan ilmu untuk pasien supaya dapat mengetahui penyebab depresi pada stroke yang diderita.

Bagi tenaga kesehatan, Penelitian ini dapat memberikan informasi dan supaya dapat mencari solusi seperti melakukan fisioterapi. Bagi perawat dan tenaga medis dapat menjadi pedoman dalam pembuatan asuhan keperawatan untuk depresi pada stroke.

\section{DAFTAR PUSTAKA}

Darussalam, M, 2011. Analisis Faktor-Faktor Yang Berhubungan Dengan Depresi Pada Pasien Stroke Di Blitar Analysis Of Factors Associated With Depression In Patients With Stroke In Blitar. Stikes Jenderal Achmad Yani Yogyakarta. Di akses pada 20 desember 2016.

Dourman, Karel. 2013. Waspadai Stroke Usia Muda .Jakarta : Generasi Sehat dan Cerdas

Gumilan, R. S. 2013. Hubungan Komponen Konsep Diri dengan Kejadian Depresi Pasien Pasca Stroke di Poli Neurologi
RSUP Dr.M.Djamil Padang Tahun 2013. Skripsi. Fakultas Keperawatan Unand

Hayulita, S, Ratna sari ,D. 2014. FaktorFaktor Yang Berhubungan Dengan Depresi Pada Pasien Paska Stroke Di Ruang Rawat Jalan Rumah Sakit Stroke Nasional (RSSN) Bukittinggi Tahun 2014. Diperoleh pada 10 Januari 2017 darihttp://ejournal.stikesyarsi.ac.id/inde x.php/JAV1N1/article/download/32/123

Karunia, E.2016. Hubungan Antara Dukungan Keluarga Dengan Kemandirian Activity Of Daily Living Pasca stroke.Jurnal Berkala Epidemiologi, Vol. 4 No. 2, Mei 2016: 213-224.Di akses pada 19 mei 2017darihttp://ejournal.unair.ac.id/index .php/JBE/article/download/2147/2462

Khomsiatun. 2015. Hubungan Status Fungsional Terhadap Depresi Pada Pasien Stroke Di Ruang Fisioterapi Di RSUD Wilayah Kabupaten Semarang. Diperoleh 20 Januari 2017 dari http://perpusnwu.web.id/karyailmiah/do cuments/4844.pdf.

Lumbantobing. 2011. Neurogeriatri. Jakarta: Balai Penerbit Fakultas Kedokteran Universitas Indonesia.

Marjoko, B. R.2014. Analisis Status Fungsional Pasien Stroke Saat Keluar Ruang Merak II RSUD Arifin Achmad Pekanbaru. Di dapat pada 21 februari 2017darihttp://repository.unri.ac.id/xml ui/bitstream/handle/123456789/4826/Ju rnal\%20Bibing\%20Rahmano\%20M.,\% 20S.Kep.pdf?sequence $=1$

Nursalam. 2016. Metodologi Penelitian Ilmu Keperawatan : Pendekatan Praktis, Edisi Empat. Jakarta: Salemba Medika.

Oktaviani, R.2017. Hubungan Dukungan Keluarga Dengan Kualitas Hidup Lanjut Usia Pasca Stroke Di Wilayah Kerja Puskesmas Gajahan Surakarta. Di akses pada 19 mei 2017 dari http://eprints.ums.ac.id/50831/1/NASK AH\%20PUBLIKASI.pdf

Pradita, D.A.2016. Hubungan Antara Faktor Demografi Dengan Depresi Pada Penderita Riwayat Stroke Di Kabupaten Gunungkidul DIY. Di akses pada19mei2017darihttp://repository.um 
y.ac.id/bitstream/handle/123456789/905

6/12.Naskah\%20Publikasi.pdf?sequenc

$\mathrm{e}=11$ \&isAllowed $=\mathrm{y}$

Ratnasari, D. 2010. Perbedaan Skor Fungsi Kognitif Stroke Iskemik Pertama Dengan Iskemik Berulang Dengan Lesi Hemisfer Kiri. Di akses pada 20 mei 2017darihttp://eprints.uns.ac.id/10092/1 /136520908201003501.pdf

Rosita, E, Suparyanto,Kusumawati,F .2012.Hubungan Tingkat Activity Daily Living (Adl) Dengan Tingkat Depresi Pada Pasien Stroke Di Paviliun Flamboyan RSUD Jombang.Jurnal Stroke;1-10. Diperoleh 08 Februari 2017

darihttp://drsuparyanto.blogspot.co.id/2 012/11/jurnal-keperawatan-hubungantingkat.html

Sulistiawaty, P.A.2017.Perbedaan Defisit Neurologis Antara Stroke Iskemik Serangan Pertama Dan Serangan Berulang. Skripsi Pendidikan Dokter Fakultas Kedokteran. Di dapat pada 21 Mei2017darihttp://eprints.ums.ac.id/502 29/27/NASKAH\%20PUBLIKASI_pup ut.pdf

Yenni. 2011. Hubungan Dukungan Keluarga Dan Karakteristik Lansia Dengan Kejadian Stroke Pada Lansia Hipertensi Di Wilayah Kerja Puskesmas Perkotaan Bukit Tinggi. Diperoleh tanggal 21 februari2017darihttp://lib.ui.ac.id/file?fi le $=$ digital/20282740-T\%20Yenni.pdf .

Yatinde,H.R. 2014. Hubungan Status Fungsional Terhadap Tingkat Depresi Pada Pasien Stroke. The lst International Nursing Conference (ICN) 2014 School Of Nursing, Jember University. Diakses pada 17 desember 2016 